\title{
Nur77 gene expression levels were involved in different ACTH-secretion autonomy between Cushing's disease and subclinical Cushing's disease
}

\author{
Yukiko Tabuchi ${ }^{1)}$, Tetsuhiro Kitamura ${ }^{1)}$, Atsunori Fukuhara ${ }^{1)}$, Kosuke Mukai ${ }^{1)}$, Toshiharu Onodera ${ }^{1)}$, \\ Yugo Miyata ${ }^{1)}$, Toshimitsu Hamasaki ${ }^{2)}$, Satoru Oshino ${ }^{3)}$, Youichi Saitoh ${ }^{4)}$, Eiichi Morii ${ }^{5)}$, Michio Otsuki ${ }^{1)}$ \\ and Iichiro Shimomura ${ }^{1)}$ \\ 1) Department of Metabolic Medicine, Osaka University Graduate School of Medicine, Osaka 565-0871, Japan \\ 2) Office of Biostatistics and Data Management, National Cerebral and Cardiovascular Center, Osaka 565-8565, Japan \\ 3) Department of Neurosurgery, Osaka University Graduate School of Medicine, Osaka 565-0871, Japan \\ 4) Department of Neuromodulation and Neurosurgery, Osaka University Graduate School of Medicine, Osaka 565-0871, Japan \\ 5) Department of Pathology, Osaka University Graduate School of Medicine, Osaka 565-0871, Japan
}

\begin{abstract}
Cushing's disease (CD) and subclinical Cushing's disease (subCD) are both diseases caused by adrenocorticotropic hormone (ACTH)-secreting pituitary adenomas. However, ACTH autonomy in subCD is weaker than in CD and there are no Cushingoid features in subCD. The differences of molecular mechanisms in ACTH autonomy between CD and subCD have not yet been reported. Therefore, we aimed to investigate the differences in molecular mechanisms of ACTHsecretion autonomy between $\mathrm{CD}$ and subCD. The study included 23 patients $[7 \mathrm{CD}, 6$ subCD, and 10 non-functioning pituitary tumors (NFTs)] who underwent transsphenoidal surgery at the Osaka University Hospital between December 2009 and October 2013. Using quantitative real-time PCR, various ACTH-related gene expressions in tumor tissues from $\mathrm{CD}$, subCD, and NFT were measured such as pro-opiomelanocortin (POMC), POMC transcription factor (Tpit, Pitx1, NeuroD1, and Nur77), POMC peptide processing enzymes (prohormone convertase: PC1/3 and PC2), and ACTH secretionrelated factors (corticotropin-releasing hormone receptor 1: CRHR1 and glucocorticoid receptor $\alpha$ : GR $\alpha$ ). Only Nur77 mRNA levels were significantly higher in CD than in subCD. Furthermore, we stained 6 CD and 6 subCD with anti-Nur77 antibody. All tumor samples from CD had Nur77 protein positive cells. On the other hand, Nur77 protein was expressed in only one tumor sample from subCD. This sample showed high expression of Nur77 mRNA. Nur77 is an important to regulate POMC transcription and negative-feedback by glucocorticoids. Nur77 gene expression levels might involve different autonomy of ACTH production between $\mathrm{CD}$ and subCD.
\end{abstract}

Key words: Nur77, Pro-opiomelanocortin, Adrenocorticotropic hormone, Cushing's disease, Subclinical Cushing's disease

CUSHING'S DISEASE (CD) is caused by an adrenocorticotropic hormone (ACTH)-secreting pituitary adenoma that leads to hypercortisolism. Cushingoid features that are called typical symptoms of CD include moon face, central obesity with buffalo hump, purple striae, thin skin, and proximal muscle weakness caused by muscle atrophy [1]. On the other hand, pituitary adenoma with autonomous ACTH secretion without

Submitted Dec. 7, 2015; Accepted Mar. 7, 2016 as EJ15-0695 Released online in J-STAGE as advance publication Mar. 29, 2016 Correspondence to: Michio Otsuki, M.D., Ph.D., Department of Metabolic Medicine, Osaka University Graduate School of Medicine, 2-2 Yamada-oka, Suita, Osaka 565-0871, Japan.

E-mail: otsuki@endmet.med.osaka-u.ac.jp any Cushingoid features has been advocated as subclinical (sub) CD [2-6].

According to the working group of the Ministry of Health, Labour and Welfare, Japan, the CD and subCD can be differentiated based on the presence of Cushingoid features and the response to the 0.5mg dexamethasone suppression test (DST) [7]. In the $0.5 \mathrm{mg}$ dexamethasone suppression test, the patients with subCD represents more than $3.0 \mu \mathrm{g} / \mathrm{dL}$ of serum cortisol, although those who has $\mathrm{CD}$ represents more than $5.0 \mu \mathrm{g} / \mathrm{dL}$. These diagnostic criteria suggest that there are some differences in ACTH secretion autonomy between $\mathrm{CD}$ and subCD. However, differences in the regulatory mechanisms of autono- 
mous ACTH secretion between $\mathrm{CD}$ and subCD are not fully understood.

With regard to ACTH biosynthesis, corticotroph cells produce the pro-opiomelanocortin (POMC) gene products. $\mathrm{POMC}$ is cleaved into mature $\mathrm{ACTH}$ by prohormone convertase $(\mathrm{PC} 1 / 3)$ and $\mathrm{ACTH}$ itself is also cleaved into melanocyte stimulating hormone by $\mathrm{PC} 2$. ACTH secretion is mainly regulated by two hormones: one is corticotrophin-releasing hormone $(\mathrm{CRH})$ which stimulates ACTH secretion through $\mathrm{CRH}$ receptor 1 (CRHR1), the other one is glucocorticoids (GCs) which inhibit ACTH secretion though glucocorticoid receptor $\alpha(\mathrm{GR} \alpha)$.

Tateno et al. [8] showed that POMC and Tpit mRNA levels were higher in $\mathrm{CD}$ than in non-functioning pituitary tumors (NFTs). PC1/3 mRNA levels were also higher in CD than in NFT. PC2 mRNA levels in CD were lower than those in NFT. Although GR $\alpha$ mRNA levels were not different between CD and NFT, CRHR mRNA levels in CD were significantly higher than those in NFT. These results suggested that the expressions of the ACTH biosynthesis and secretion-related genes were clearly different between CD and NFT. However, there was no study about the differences in molecular mechanisms among $\mathrm{CD}$, subCD and NFT.

Nur77 is known as nerve growth factor-inducible factor-B and a member of orphan nuclear receptors. Nur77 is induced by CRH and enhances POMC promoter activity by binding to the Nur response element (NurRE) [9]. On the other hand, Nur77 is also involved in the GC-induced suppression of POMC gene. Nur77 binds to the negative glucocorticoid responsive element (nGRE) in the POMC promoter and inhibits its expression [10]. Collectively, Nur77 seems to be involved in POMC regulation in both $\mathrm{CRH}$-mediated POMC induction and GC-mediated POMC suppression. However, these functions of Nur77 have been shown in AtT-20 cells (mouse derived ACTH-producing cell line), and not in human $\mathrm{CD}$ and subCD samples.

In this study, we examined various ACTH related gene expression, including Nur77, and investigated the molecular differences between subCD and CD.

\section{Materials and Methods}

\section{Study design}

Among 194 patients at the Osaka University Hospital who underwent transsphenoidal surgery (TSS) for the removal of pituitary tumors between December 2009 and October 2013, tissue samples from 17 patients with ACTH secreting adenoma (ACTHoma), including subCD and $\mathrm{CD}$, were taken. High quality mRNA was extracted from the 13 samples. We studied these 13 samples and used 10 NFTs as control samples.

\section{Diagnostic criteria}

The diagnosis of $\mathrm{CD}$ was established based on Cushingoid features; laboratory data, including lack of serum cortisol suppression in the $0.5 \mathrm{mg}$ DST (more than $5.0 \mu \mathrm{g} / \mathrm{dL}$ ), loss of serum cortisol circadian rhythm, paradoxical response of plasma ACTH in the desmopressin (DDAVP) test, serum cortisol suppression in the $8 \mathrm{mg}$ DST (less than half of the basal levels), and/or hyper response of plasma ACTH to human $\mathrm{CRH}(\mathrm{hCRH})$; and the presence of a pituitary tumor on magnetic resonance imaging (MRI). SubCD was diagnosed by the lack of Cushingoid phenotype and presence of a pituitary tumor in addition to loss of serum cortisol circadian rhythm and lack of serum cortisol suppression in the $0.5 \mathrm{mg}$ DST (more than $3.0 \mu \mathrm{g} / \mathrm{dL}$ ). The evaluation criteria used in the DDAVP test, $8 \mathrm{mg}$ DST, hCRH test, and MRI for the diagnosis of subCD were similar to those applied to CD. Clinical characteristics of participating patients are summarized in Table 1. There was no difference in endocrinological data between subCD and NFT groups except for morning cortisol levels and serum cortisol levels after 0.5 mg DST. All patients underwent TSS and ACTH production by pituitary adenoma was diagnosed by positive immunoreactivity for ACTH as shown in Fig. 1. By contrast, all of NFTs were negative immunoreactivity for ACTH. The study protocol was approved by the Institutional Review Board for Clinical Research at Osaka University Hospital (Protocol No. 13042) Ethics Committee and the study was performed according to the Helsinki declaration. Each patient signed an informed consent for participation.

\section{Hormonal assays}

Plasma ACTH was measured by electrochemiluminescence immunoassay (ECLusys ACTH kit, Roche Diagnostics, Basel, Switzerland). Serum cortisol was measured by chemiluminescent enzyme immunoassay (Access cortisol kit, Beckman Coulter, Brea, CA). The sensitivity of the kit is $0.4 \mu \mathrm{g} / \mathrm{dL}$, with an intra-assay coefficient of variation $(\mathrm{CV})$ of $<4.3 \%$ and inter-assay $\mathrm{CV}$ of $<5.9 \%$. 
Table 1 Clinical characteristics and endocrinological profile of patients with NFT, subCD and CD

\begin{tabular}{lccc}
\hline & NFT & subCD & CD \\
\hline Sex (male) & $60.0 \%(6 / 10)$ & $16.7 \%(1 / 6)$ & $28.6 \%(2 / 7)$ \\
Age (years) & $58.4 \pm 17.2$ & $50.2 \pm 7.8$ & $43.3 \pm 19.1$ \\
BMI $\left(\mathrm{kg} / \mathrm{m}^{2}\right)$ & $22.8 \pm 2.8$ & $24.1 \pm 4.7$ & $25.0 \pm 3.6$ \\
Tumor size $(\mathrm{mm})$ & $24.6 \pm 4.9$ & $19.1 \pm 19.5$ & $11.9 \pm 7.9^{\# \# \#}$ \\
Macroadenoma $(>10 \mathrm{~mm})$ & $100 \%(10 / 10)$ & $66.7 \%(4 / 6)$ & $57.1 \%(4 / 7)$ \\
Morning ACTH levels $(\mathrm{pg} / \mathrm{mL})$ & $27.6 \pm 13.9$ & $32.9 \pm 18.6$ & $112.0 \pm 43.7^{\S \S, \# \#}$ \\
Morning cortisol levels $(\mu \mathrm{g} / \mathrm{dL})$ & $6.2 \pm 4.9$ & $12.6 \pm 2.4^{\#}$ & $20.1 \pm 5.6^{\S, \# \#}$ \\
Midnight cortisol levels $(\mu \mathrm{g} / \mathrm{dL})$ & None & $10.5 \pm 4.4$ & $33.8 \pm 11.9^{\S \S}$ \\
Serum cortisol levels $(\mu \mathrm{g} / \mathrm{dL})$ after $0.5 \mathrm{mg}$ DST & $1.3 \pm 0.5$ & $10.7 \pm 3.9^{\# \# \#}$ & $35.8 \pm 21.4^{\S, \# \#}$ \\
\hline Data ar m
\end{tabular}

Data are mean \pm SD. ${ }^{\S} P<0.05,{ }^{\S \S} P<0.01$, vs. SubCD. ${ }^{\#} P<0.05,{ }^{\# \#} P<0.001, v s$. NFT. Statistical analyses were performed by Student's $t$-test and Chi-square test. DST, dexamethasone suppression test
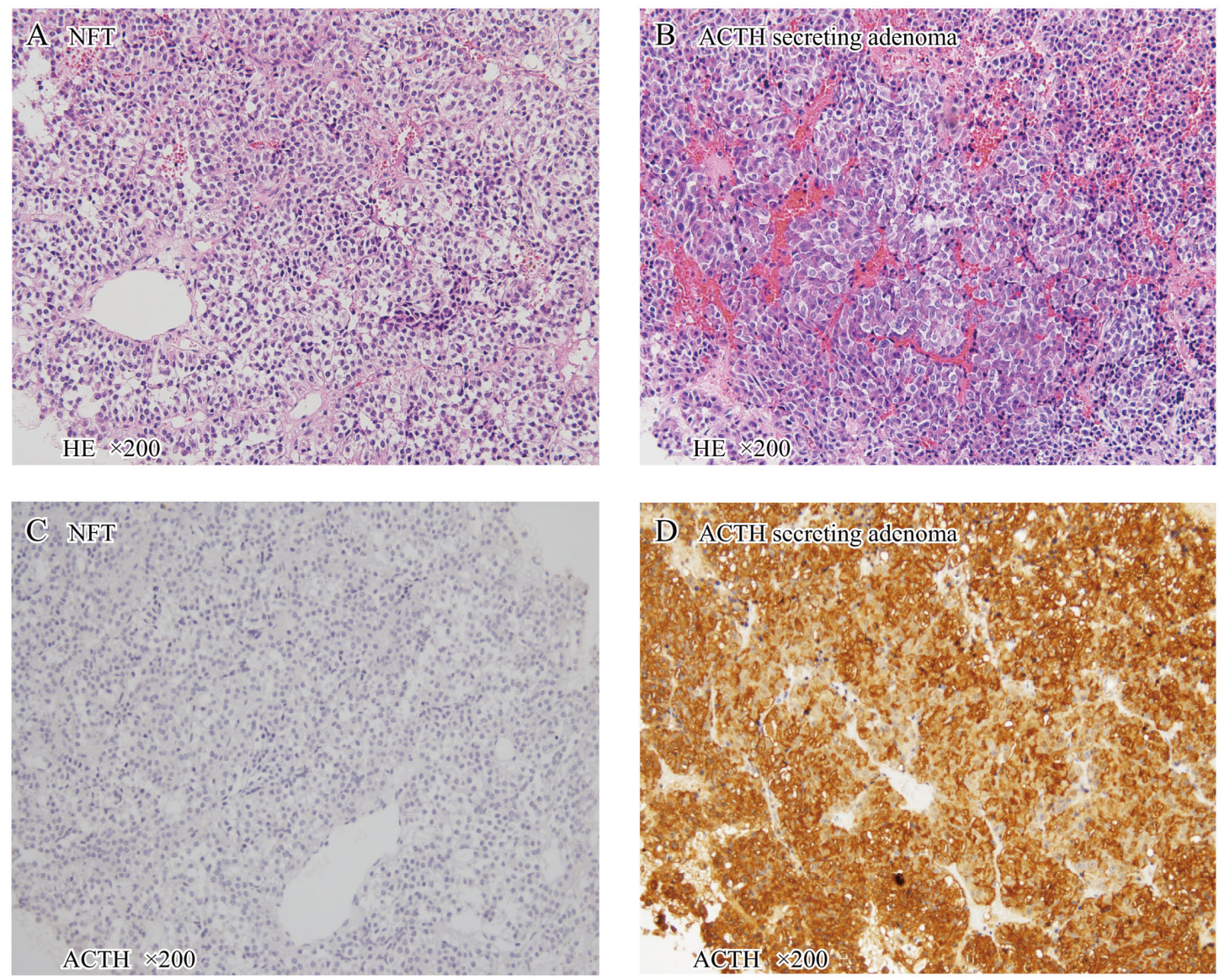

Fig. 1 Representation of the histopathological and immunohistochemical studies of tissue specimens from the pituitary tumors

(A-B) Hematoxylin and eosin staining (magnification, $\times 200),($ C-D) Immunostaining for ACTH (magnification, $\times 200$ ). 


\section{Preparation of tissue specimens}

Tissue specimens from the surgically-excised pituitary tumors were used for analysis. One portion of the surgical tissue specimens was subjected to histological analysis, whereas the remaining tissue specimens were immediately placed into RNAlater ${ }^{\circledR}$ solution (Qiagen, Valencia, CA) or frozen in liquid nitrogen for RNA extraction.

\section{Quantitative real-time PCR ( $\mathrm{PPCR}$ )}

Total RNA was extracted from 1.5-5.0 mg of pituitary tumor samples using the RNeasy micro kit (Qiagen) according to the manufacturer's recommended protocol, and RNA yields were $>600 \mathrm{ng} /$ sample. RNA quality was confirmed by $28 \mathrm{~S}: 18 \mathrm{~S}$ rRNA ratio on an agarose gel, and degraded RNA were excluded. The RNA purity was determined by measuring the $260 / 280$ and 260/230 ratios with a Nanodrop instrument, and these ratios were between 1.8 and 2.1, indicating a high level of RNA purity. For synthesis of cDNA, $210 \mathrm{ng}$ of total RNA was reverse transcribed with the Transcriptor First Strand cDNA Synthesis Kit (Roche, Indianapolis, IN). qPCR was performed using the LightCycler system (FastStart DNA Master SYBR Green I, Roche) according to the manufacturer's protocol. Glyceraldehyde-3phosphate dehydrogenase (GAPDH) was used as the housekeeping gene. The sequences of primers used for qPCR are listed in Table 2.

\section{Immunohistochemical staining}

Tissue sections from the pituitary tumors were stained with hematoxylin and eosin. ACTH and Nur77 proteins were examined immunohistochemically with an anti-ACTH antibody (M3501, Dako, Carpinteria, CA) and an anti-Nur77 antibody (LS-B114, LSBio, Seattle, WA), respectively. Antigens were retrieved with the Pascal pressurized heating chamber (Dako). The sections were incubated with the anti-ACTH antibody (1:100) and the anti-Nur77 antibody (1:40), and treated with the ChemMate EnVision kit (Dako). Diaminobenzidine was used as a chromogen.

\section{Statistical analysis}

Data are expressed as mean $\pm \mathrm{SD}$, or numbers with percentages as appropriate. Continuous variables were compared pairwise between groups by using the Student's $t$-test. Prior to the analysis, data were logtransformed because data were not normally distributed. Categorical variables were analyzed by using the chi-square test. A $p$ value $<0.05$ was considered statistically significant.

\section{Results}

\section{POMC and POMC transcription-related gene expres- sions}

In order to initially investigate the difference in ACTH-secretion autonomy among CD, subCD, and NFT, we studied POMC mRNA levels (Fig. 2). POMC mRNA levels were significantly higher in CD and subCD than in NFT $(P<0.001)$. However, there were no significant differences in POMC mRNA levels between $\mathrm{CD}$ and subCD. Next, we investigated Tpit, Pitx1, NeuroD1, and Nur77 gene expressions (Fig. 3). Although Tpit mRNA levels were similar in subCD compared with those in $C D$, this mRNA levels were significantly higher in $\mathrm{CD}$ and subCD than in NFT $(P<0.001)$. Nur77 mRNA levels were significantly higher in CD than in subCD and NFT $(P<$ 0.05). Pitx1 mRNA levels were similar among $C D$, subCD, and NFT. NeuroD1 mRNA levels were significantly lower in subCD than in NFT $(P<0.05)$ and tended to be lower in CD than in NFT $(P=0.053)$.

Table 2 Primers used in quantitative real-time RT-PCR (human)

\begin{tabular}{|c|c|c|}
\hline Gene & & Sequence \\
\hline \multirow{2}{*}{ GAPDH } & Forward & 5'-CCTGTTCGACAGTCAGCCG-3' \\
\hline & Reverse & 5'-CGACCA AATCCGTTGACTCC-3' \\
\hline \multirow{2}{*}{ POMC } & Forward & 5'-CTACGGCGGTTTCATGACCT-3' \\
\hline & Reverse & 5'-CCCTCACTCGCCCTTCTTG-3' \\
\hline \multirow{2}{*}{ Nur77 } & Forward & 5'-ATGCCCTGTATCCAAGCCC-3' \\
\hline & Reverse & 5'-GTGTAGCCGTCCATGAAGGT-3' \\
\hline \multirow{2}{*}{ Tpit } & Forward & 5'-CTTTTGCCAAAGCCTTCTTG-3' \\
\hline & Reverse & 5'-AGCGGCATACTGGTAATTGG-3' \\
\hline \multirow{2}{*}{$\mathrm{PC} 1 / 3$} & Forward & 5'-CGCTGACCTGCACAATGACT-3' \\
\hline & Reverse & 5'-CAGACAACCAGGTGCTGCAT-3' \\
\hline \multirow{2}{*}{ PC2 } & Forward & 5'-CTTGCAAAGGCCAAGAGAAG-3' \\
\hline & Reverse & 5'-TTTCGGTCAAATCCTTCCTG-3' \\
\hline \multirow{2}{*}{ CRHR1 } & Forward & 5'-CTCCTGGGCATCACCTACAT-3' \\
\hline & Reverse & 5'-GACACAAAGAAGCCCTGGAA-3' \\
\hline \multirow{2}{*}{ GR $\alpha$} & Forward & 5'-GAACTGGCAGCGGTTTTATC-3' \\
\hline & Reverse & 5'-CAGCTAACATCTCGGGGAAT-3' \\
\hline \multirow{2}{*}{ Pitx1 } & Forward & 5'-CCCAACTCGGGCCTCAACAA-3' \\
\hline & Reverse & 5'-GCCGTAGCCAAACGACGAGT-3' \\
\hline \multirow{2}{*}{ NeuroD1 } & Forward & 5'-GCCCCAGGGTTATGAGACTA-3' \\
\hline & Reverse & 5'-GCTCCTCGTCCTGAGAACTG-3' \\
\hline
\end{tabular}

POMC, Proopiomelanocortin; PC, Prohormone convertase; CRHR1, Corticotropin releasing hormone receptor1; GR $\alpha$, Glucocorticoid receptor $\alpha$ 


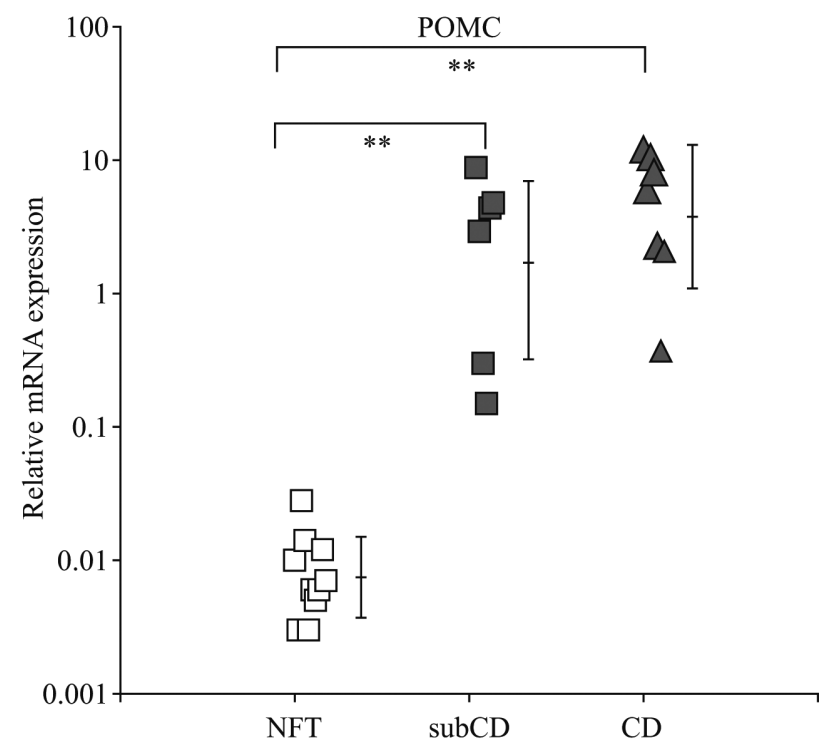

Fig. 2 POMC gene expression levels in NFT, subCD and CD

Data points represent individual tumors and bars represent mean $\pm \mathrm{SD}$ data for the group. $* * P<0.001$
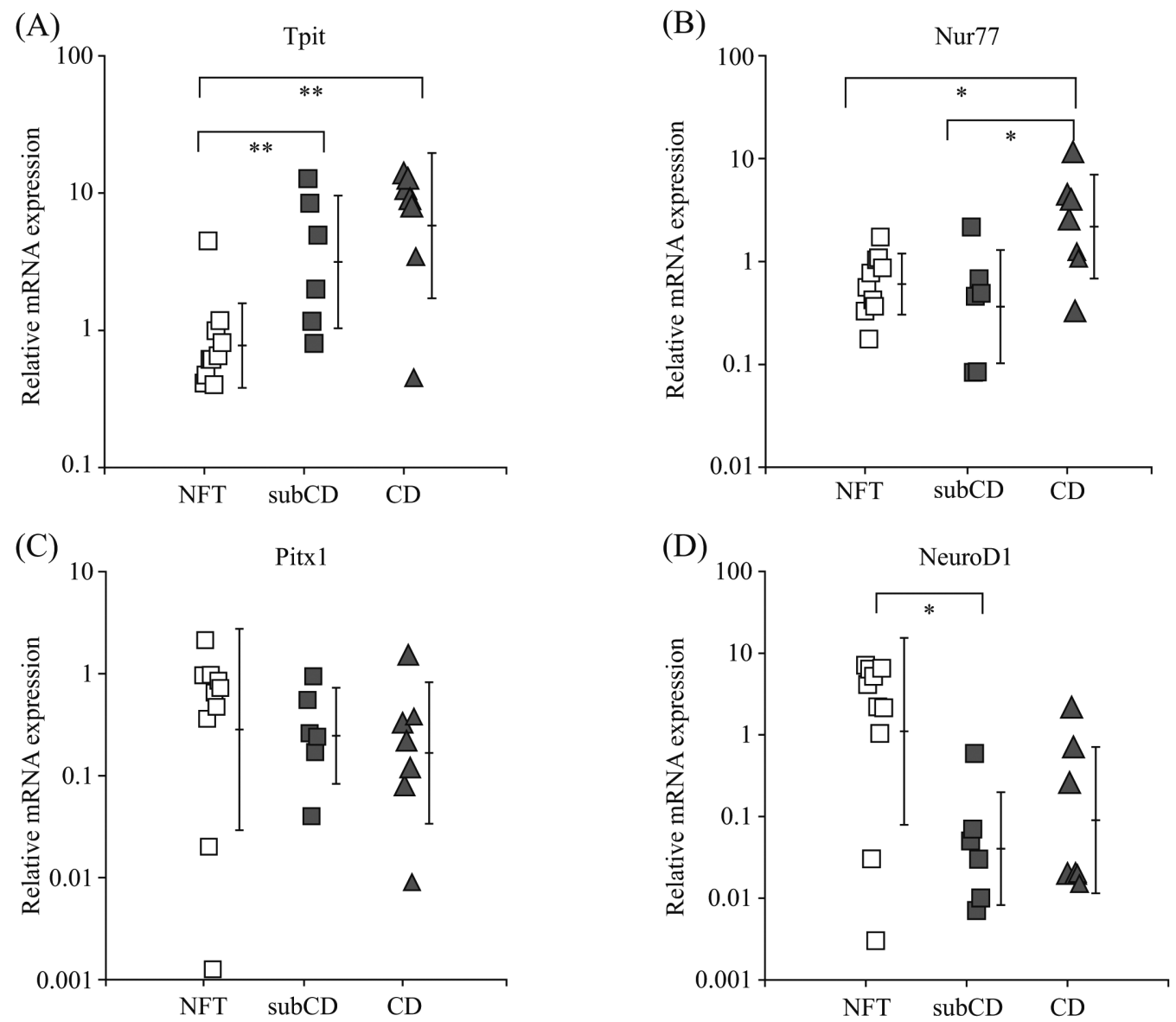

Fig. 3 POMC transcription-related gene expression levels in NFT, subCD and CD

(A) Tpit, (B) Nur77, (C) Pitx1, (D) NeuroD1. Data points represent individual tumors and bars represent mean $\pm \mathrm{SD}$ data for the group. $* P<0.05$, ${ }^{* *} P<0.001$ 
POMC peptide processing-related gene expressions

POMC peptide processing genes such as $\mathrm{PC} 1 / 3$ and $\mathrm{PC} 2$ play an important role in ACTH production. $\mathrm{PC} 1 / 3$ mRNA levels were not significantly different among three groups (Fig. 4A). PC2 mRNA levels were not significantly different between $\mathrm{CD}$ and subCD, although those in NFT were significantly higher compared with those in $\mathrm{CD}$ and subCD $(P<0.001)$ (Fig. 4B).

\section{ACTH secretion-related gene expressions}

We next investigated CRHR1 mRNA levels, specific receptors for CRH (Fig. 5A). The mRNA levels of CRHR1 were not significantly different between subCD and $\mathrm{CD}$. However, those in $\mathrm{CD}$ were signifi-
(A)

$\mathrm{PC} 1 / 3$

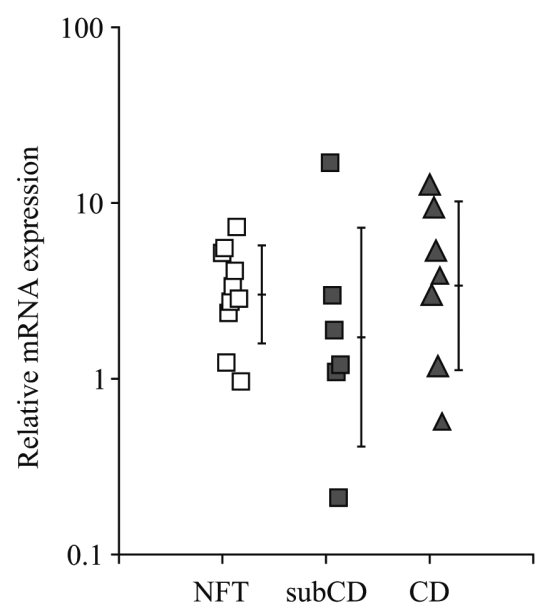

(B)

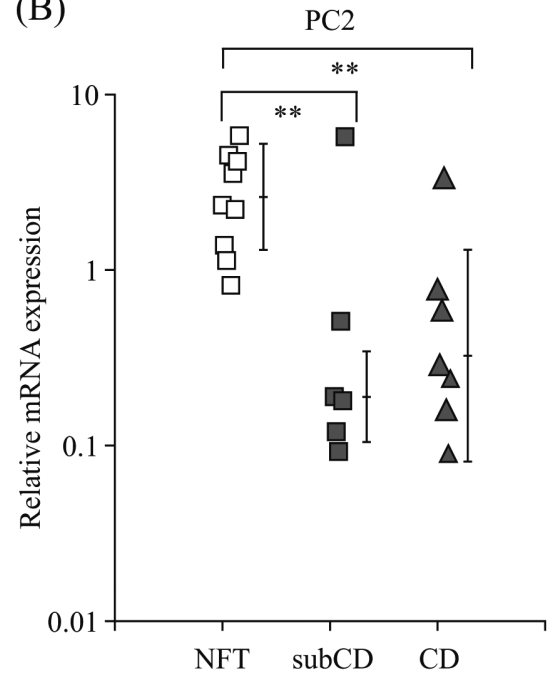

Fig. 4 POMC peptide processing-related gene expression in NFT, subCD and CD

(A) $\mathrm{PC} 1 / 3$, (B) PC2. Data points represent individual tumors and bars represent mean \pm SD data for the group. ${ }^{* *} P<0.001$

(A)

CRHR1

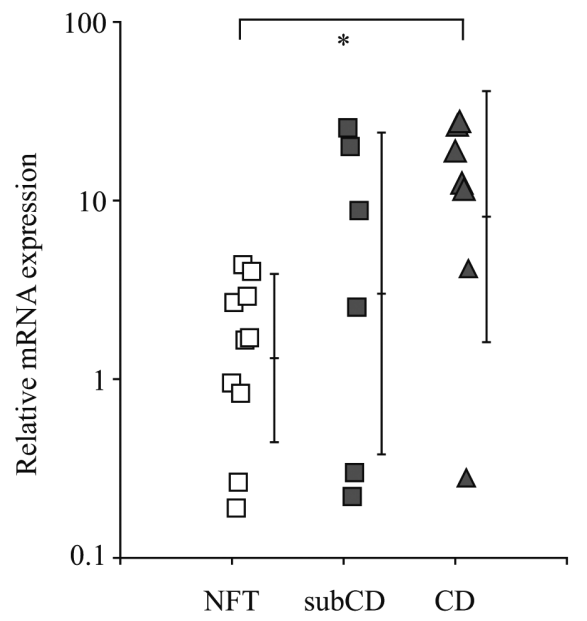

(B)

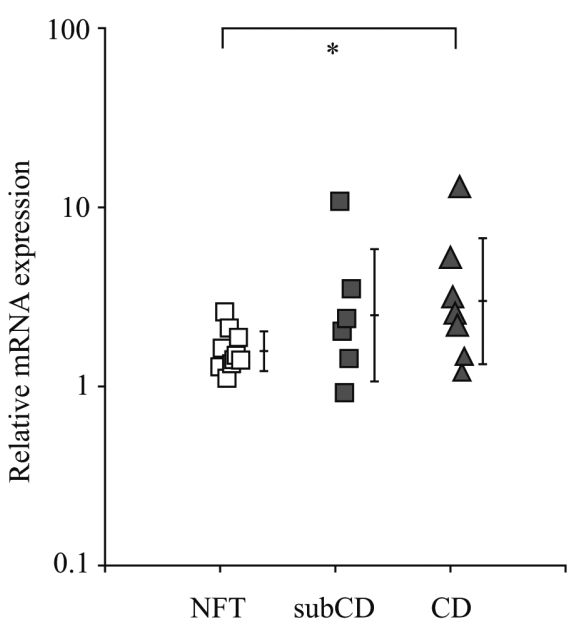

Fig. 5 ACTH secretion-related gene expression in NFT, subCD and CD

(A) CRHR1, (B) GR $\alpha$. Data points represent individual tumors and bars represent mean \pm SD data for the group. ${ }^{*} P<0.05$ 
cantly higher than those in NFT $(P<0.05)$.

\section{Gene expression related to negative feedback of $P O M C$ promoter by GCs}

GCs exert negative feedback at both the pituitary and the hypothalamic levels. We examined the GR $\alpha$ mRNA levels in all tumor groups. The mRNA levels of GR $\alpha$ in $\mathrm{CD}$ were as same as subCD. However, those in CD were significantly higher than those in NFT $(P$ $<0.05$ ) (Fig. 5B).

\section{Immunohistochemical staining of Nur77 protein}

Because only Nur77 mRNA levels were significantly different between $\mathrm{CD}$ and subCD, we also measured Nur77 protein expression. We stained available $6 \mathrm{CD}$ and 6 subCD samples with Nur77 antibodies. Although all of the cases of CD had Nur77 protein positive cells (Fig. 6), only one case of subCD expressed the Nur77 protein. This subCD sample also showed high Nur77 mRNA levels.

\section{Discussion}

In the present study, we compared the various gene expression profiles in pituitary tumor tissues of patients with $\mathrm{CD}$, subCD, and NFT by using qPCR. The study provided the first evidence for the differences of the gene expression levels involved in the regulation of POMC transcription, POMC peptide processing, and $\mathrm{ACTH}$ secretion between $\mathrm{CD}$ and subCD. We found that Nur77 mRNA levels in CD were significantly higher than in subCD, although the Nur77 mRNA lev- els in subCD were similar to that in NFT.

In AtT20 cells, Nur77 is induced and activated by $\mathrm{CRH}$, and activation of Nur77 increases POMC gene expression $[11,12]$. However, it has been documented that CRH mRNA synthesis and secretion in CD are inhibited by hypercortisolism. Therefore, Nur77 expression might be regulated by $\mathrm{CRH}$-independent signaling pathway in CD. Choi et al. showed that hypoxia-inducible factor (HIF)-1 $\alpha$ directly activated Nur77 gene expression in von Hippel-Lindaumutated renal cell carcinomas [13]. In addition to HIF- $1 \alpha$, interleukin-1, $\beta$-catenin, and $\mathrm{c}$-fos/c-jun are also upstream stimulatory factors of Nur77 [14, 15]. These results suggest the existence of a CRHindependent Nur77 induction pathway, which could play an important role in POMC expression in CD. However whether these factors involve Nur77 expression in $\mathrm{CD}$ is unknown. Further study is needed to elucidate the molecular mechanism of Nur77 expression in $\mathrm{CD}$.

POMC mRNA levels were significantly higher in CD than in NFT, a finding consistent with that of a previous study by Tateno et al. [8]. In the anterior lobe of the pituitary gland, POMC gene is expressed in ACTH-producing cells, and its expression is regulated by various transcription factors, such as Tpit and Nur77. Tpit is exclusively expressed in pituitary POMC-expressing lineages, and is essential for cellspecific transcription of the POMC gene [16]. Maria et al. reported that Tpit and Nur77 cooperatively induce POMC gene expression [17]. The present study showed that there was no significant difference
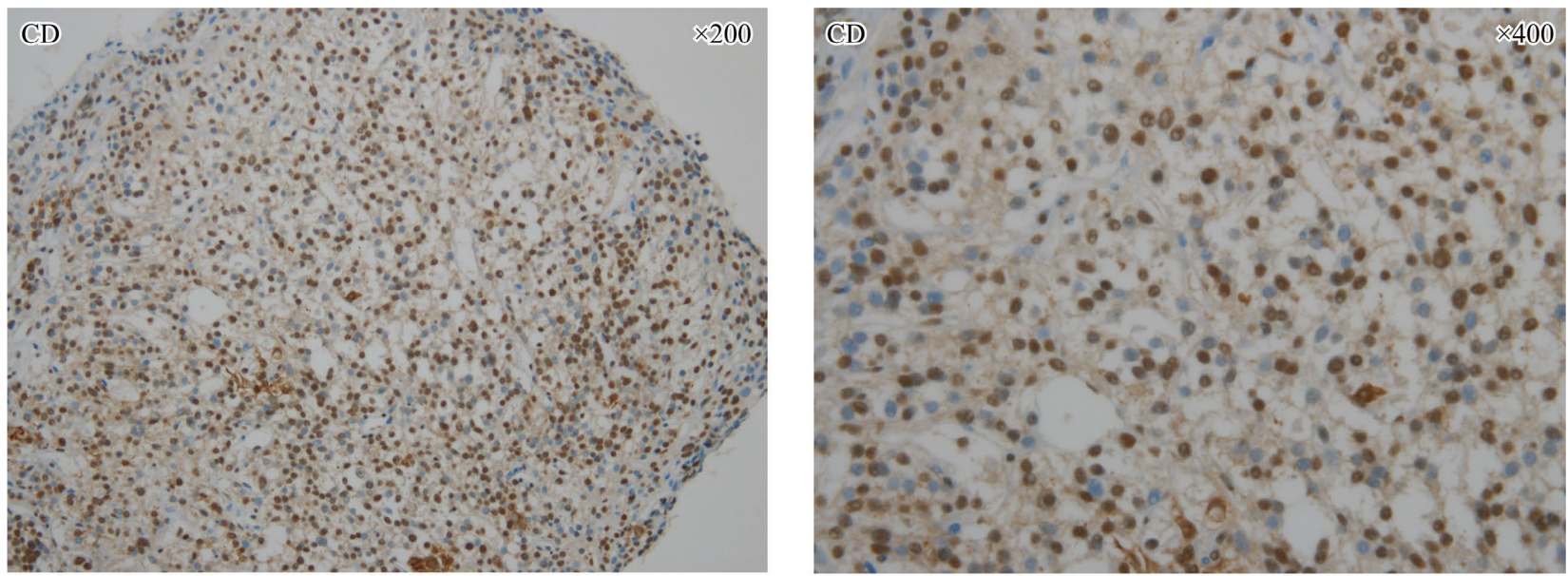

Fig. 6 Representative histopathological and immunohistochemical studies of tissue specimens from CD Immunostaining for Nur77 protein (magnification, $\times 200$ and $\times 400$ ). 
in POMC mRNA levels between subCD and CD. The distribution of POMC mRNA levels was more extensive in subCD than in CD, although Tpit mRNA levels were similar between them. Thus, Nur77 is the only factor whose expression levels are significantly different between subCD and $\mathrm{CD}$. Regarding the immunostaining of Nur77 in tissue sections, Nur77 protein was prominently stained and located in the nucleus in all CD samples. In contrast, there was only one subCD sample that showed positive staining for Nur77. This sample also showed high Nur77 mRNA levels as well as high POMC mRNA levels. Interestingly, a strong correlation was found between Nur77 and POMC mRNA levels in $7 \mathrm{CD}$ and 6 subCD ( $\mathrm{r}=0.612, P=0.026$, data not shown). These results suggest that Nur77 levels might be involved in POMC gene expression.

Based on our hypothesis that Nur77 levels are involved in POMC gene expression, we have done a comparative analysis of Nur77 mRNA levels in 13 ACTHomas (including CD and subCD) and 10 NFTs. As shown in Supplementary Fig. 1, Nur77 mRNA levels varied widely in ACTHomas but were not significantly different from those in NFTs. However, since Nur77 mRNA levels in some ACTHomas were higher than those in NFTs, it was assumed that ACTHomas were divided into two distinct subgroups (H: Nur77-high ACTHoma, and L: Nur77low ACTHoma in Supplementary Fig.1). The clinical diagnosis of $\mathrm{CD}$ was established in four of five patients $(80 \%)$ in Nurr77-high group, and three of eight patients $(37.5 \%)$ in Nurr77-low group. We could not completely classify ACTHomas into CD and subCD according to Nur77 gene expression levels. We also did cluster analysis (The Cluster version 3.0, and Java TreeView) using seven genes (Nur77, POMC, Tpit, PC1/3, PC2, CRHR1, and GR $\alpha$ ). Twoway hierarchical clustering produced a dendrogram with tumor samples divided into 3 distinct subgroups (Supplementary Fig. 2). In this analysis, subgroup A was completely correspondent with Nur77-high ACTHoma, and subgroup C with NFT. Furthermore, subgroup B was completely correspondent with Nur77-low ACTHoma. Our results demonstrated 7 ACTH-related gene expressions including POMC, Tpit, and PC1/3 were significantly higher in Nur77high ACTHoma compared to Nur77-low ACTHoma. Although there was relatively small number analysis, we suggested that Nur77 might have a possibil- ity to define ACTH-related genes. Further prospective studies in large number of patients are needed to confirm our findings.

Fukuoka et al. showed that the Epidermal Growth Factor (EGF)-mediated pathway play an important role in POMC gene expression and inhibiting EGF receptor pathway may a target for treating $\mathrm{CD}$. POMC promoter activity by EGF required a -323 to $-200 \mathrm{bp}$ element that includes Tpit/Pitx sites [18]. Recently Reincke et al. reported that ubiquitin-specific peptidase 8 (USP8) gene mutations were found in a high percentage of corticotroph adenomas [19, 20]. The USP8 gene mutations enhanced the proteolytic cleavage and catalytic activity of USP8. USP8 cleavage induced the increase in deubiqutination of the EGF receptor, suppressed its downregulation and kept activating EGF signaling. USP8 mutants enhanced promoter activity of the gene encoding POMC [19]. On the other hand, Nur77 is induced by $\mathrm{CRH}$ and enhances POMC promoter activity by binding to the NurRE, centered around -395 bp [9]. Nur77 binds to the nGRE in the POMC promoter and inhibits its expression [10]. These data come to the conclusion that Nur77 is involved in POMC regulation in both CRH-mediated POMC induction and GC-mediated POMC suppression. Unfortunately we did not examine the relationship between POMC and Nur77 gene expressions and the USP8 gene mutations because genetic analysis such as the USP8 gene mutations using patient's tumor samples was not included in our study protocol. However we suggested that there is no direct interaction between EGF receptor signaling and Nur77.

In conclusion, we investigated ACTH-related gene expression levels between subCD and CD. Nur77 is important for regulation of POMC gene transcription and negative feedback by GCs. This is the first report that Nur77 mRNA showed high expression in human CD. This study may serve as a step towards the definition of a new molecular taxonomy of pituitary tumors, and demonstrates the significance of gene expression profiling in the diagnosis of ACTHomas.

\section{Disclosure}

Department of Neuromodulation and Neurosurgery is supported by Teijin Pharma Led. Other entire authors except above author have any potential conflicts of interest associated with this study. 


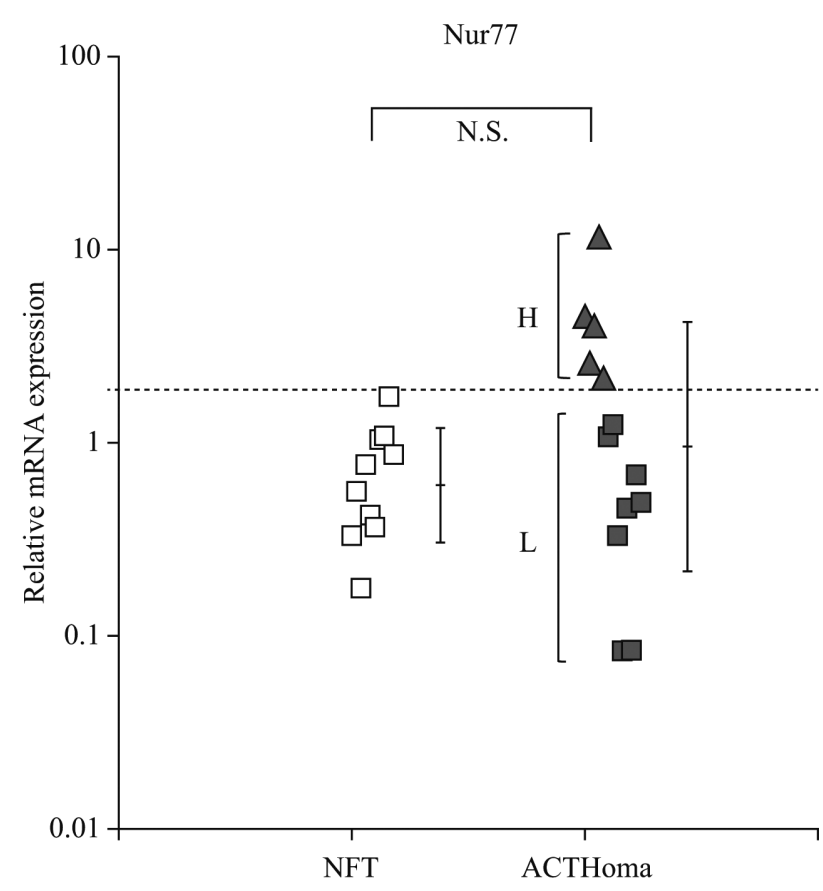

Supplementary Fig. 1 Nur77 expression levels in NFT and ACTHoma

Open boxes: NFT $(\mathrm{n}=10)$, Closed triangles: H, Nur77-high ACTHoma $(\mathrm{n}=5)$; Closed boxes: L, Nur77low ACTHoma $(n=8)$. Data points represent individual tumors and bars represent mean $\pm \mathrm{SD}$ data for the group. N.S., not significant

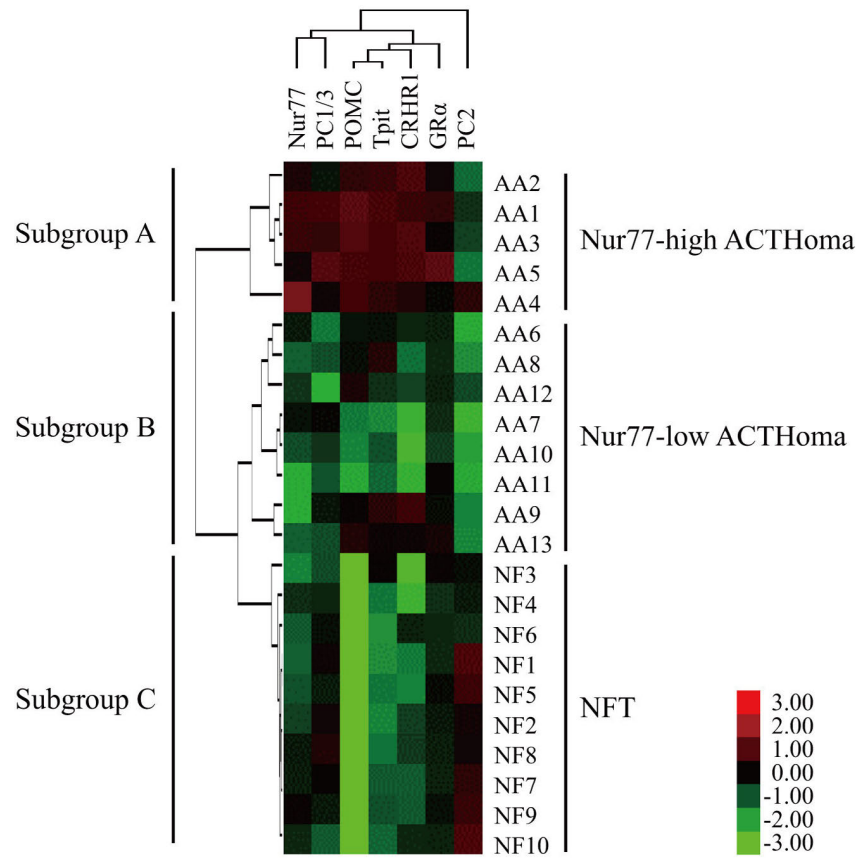

Supplementary Fig. 2 Molecular subtype classification of ACTHomas and NFTs based on hierarchical cluster analysis using 7 genes (Nur77, POMC, Tpit, PC1/3, PC2, CRHR1, and GR $\alpha$ ). Two-way hierarchical clustering produced a dendrogram with tumor samples divided into three distinct subgroups.

\section{References}

1. De Martin M, Pecori Giraldi F, Cavagnini F (2006) Cushing's disease. Pituitary 9: 279-287.

2. Sakai K, Horiba N, Sakai Y, Hizuka N, Suda T, et al. (1994) A case of preclinical Cushing's disease only accompanied by obesity and glucose intolerance. Nihon Naibunpi Gakkai Zasshi 70: 726 (Abstract) (In Japanese).

3. Takao T, Mimoto T, Yamamoto M, Hashimoto K (2001) Preclinical Cushing disease. Arch Intern Med 161: 892-893.

4. Nagai T, Imamura M, Misumi S, Mori M (2002) Subclinical Cushing's disease accompanied by malignant hypertension and diabetes mellitus. Intern Med 41: 566-570.

5. Minami I, Tateno T, Yoshimoto T, Doi M, Izumiyama $\mathrm{H}$, et al. (2006) Subclinical Cushings disease with amelioration of metabolic comorbidities after removal of pituitary tumor. Intern Med 45: 1231-1235.

6. Kageyama K, Moriyama T, Sakihara S, Kawashima S,
Suda T (2003) A case of preclinical Cushing's disease, accompanied with thyroid papillary carcinoma and adrenal incidentaloma. Endocr J 50: 325-331.

7. Kageyama K, Oki Y, Sakihara S, Nigawara T, Terui K, et al. (2013) Evaluation of the diagnostic criteria for Cushing's disease in Japan. Endocr J 60: 127-135.

8. Tateno T, Izumiyama H, Doi M, Yoshimoto T, Shichiri $\mathrm{M}$, et al. (2007) Differential gene expression in ACTH -secreting and non-functioning pituitary tumors. Eur $J$ Endocrinol 157: 717-724.

9. Philips A, Lesage S, Gingras R, Maira MH, Gauthier $Y$, et al. (1997) Novel dimeric Nur77 signaling mechanism in endocrine and lymphoid cells. Mol Cell Biol 17: 5946-5951.

10. Okabe T, Takayanagi R, Adachi M, Iwasaki K, Nawata H (1998) Nur77, a member of the steroid receptor superfamily, antagonizes negative feedback of ACTH synthesis and secretion by glucocorticoid in pituitary corticotrope cells. J Endocrinol 156: 169-175. 
11. Perez-Castro C, Renner U, Haedo MR, Stalla GK, Arzt E, et al. (2012) Cellular and molecular specificity of pituitary gland physiology. Physilo Rev 92: 1-38.

12. Kovalovsky D, Refojo D, Liberman AC, Holsboer F, Pereda MP, et al. (2002) Activation and induction of NUR77/NURR1 in corticotrophs by CRH/cAMP: involvement of calcium, protein kinase A, and MAPK pathways. Mol Endocrinol 16: 1638-1651.

13. Choi JW, Park SC, Kang GH, Liu JO, Youn HD (2004) Nur77 activated by hypoxia-inducible factor-1alpha overproduces proopiomelanocortin in von HippelLindau-mutated renal cell carcinoma. Cancer Res 64: 35-39.

14. Kovalovsky D, Paez Pereda M, Labeur M, Renner U, Holsboer F, et al. (2004) Nur77 induction and activation are necessary for interleukin-1 stimulation of proopiomelanocortin in AtT-20 corticotrophs. FEBS Lett 563: 229-233.

15. Wu H, Lin Y, Li W, Sun Z, Gao W, et al. (2011) Regulation of Nur77 expression by beta-catenin and its mitogenic effect in colon cancer cells. FASEB J 25:
192-205.

16. Lamolet B, Pulichino AM, Lamonerie T, Gauthier Y, Brue T, et al. (2001) A pituitary cell-restricted T box factor, Tpit, activates POMC transcription in cooperation with Pitx homeoproteins. Cell 104: 849-859.

17. Maira M, Couture C, Le Martelot G, Pulichino AM, Bilodeau S, et al. (2003) The T-box factor Tpit recruits SRC/p160 co-activators and mediates hormone action. $J$ Biol Chem 278: 46523-46532.

18. Fukuoka H, Cooper O, Ben-Shlomo A, Mamelak A, Ren SG, et al. (2011) EGFR as a therapeutic target for human, canine, and mouse ACTH-secreting pituitary adenomas. J Clin Invest 121: 4712-4721.

19. Sbiera S, Deutschbein T, Weigand I, Reincke M, Fassnacht M, et al. (2015) The new molecular landscape of Cushing's disease. Trends Endocrinol Metab 26: 573-583.

20. Reincke M, Sbiera S, Hayakawa A, Theodoropoulou M, Osswald A, et al. (2015) Mutations in the derbiquitinase gene USP8 cause Cushing's disease. Nat Genet 47: 31-38. 